\title{
Effects of filtration process on the minor constituents and oxidative stability of virgin olive oil during 24 months storage time
}

\author{
Esmaeil Ghanbari Shendi ${ }^{1, *}$, Dilek Sivri Ozay ${ }^{1}$ and Mucahit Taha Ozkaya ${ }^{2}$ \\ ${ }^{1}$ Hacettepe University, Department of Food Engineering, Ankara 06800, Turkey \\ 2 Ankara University, Department of Horticulture, Ankara 06110, Turkey
}

Received 10 April 2020 - Accepted 15 June 2020

\begin{abstract}
In this study, effects of filtration and storage time on the chemical composition and sensory profile of the virgin olive oil extracted from a local olive cultivar known as Saurani grown in Hatay province of Turkey were determined. Before storing both filtered (F) and unfiltered (UF) samples were categorized as virgin olive oil (VOO) according to the International Olive Council (IOC) standards. The main characteristics of Saurani olive oils were: a mid-oleic acid (69.3\%), low linoleic acid (7.7\%) and high linolenic $(0.85 \%)$ acid contents with high total phenolic content (522.34 ppm as gallic acid). Monitoring of stored samples for 24 months revealed significant differences between F and UF olive oils in terms of free acidity and peroxide values, and filtered oils appeared to be better protected against hydrolysis and oxidative deterioration. Free fatty acidity of $\mathrm{F}$ and UF olive oil samples which were initially $0.4 \%$ and reached to $0.9 \%$ after 23 and 11 months' storage respectively. Peroxide values of the F and UF olive oil samples were exceeded the limit of IOC standard $(20 \mathrm{mEq}$ oxygen $/ \mathrm{kg}$ oil) after ten and three months, respectively. Total phenol contents were higher in UF samples and their contents decreased with storing. Luteolin was the most abundant phenolic compound and tyrosol contents of both F and UF samples reached maximum values in the ninth month of storage. It seemed filtration had no detectable effect on tocopherols contents and about $50 \%$ of $\alpha$-tocopherol destroyed after 24 months' storage.
\end{abstract}

Keywords: Olive oil / saurani / phenolic compounds / tocopherol / storage

Résumé - Effets du processus de filtration sur les constituants mineurs et la stabilité oxydative de l'huile d'olive vierge pendant une période de stockage de $\mathbf{2 4}$ mois. Dans cette étude, les effets de la filtration et du temps de stockage sur la composition chimique et le profil sensoriel de l'huile d'olive vierge extraite d'un cultivar d'olive local connu sous le nom de Saurani, cultivé dans la province de Hatay en Turquie, ont été déterminés. Avant d'être stockés, les échantillons filtrés (F) et non filtrés (UF) ont été classés comme huile d'olive vierge (VOO) selon les normes du Conseil oléicole international (COI). Les principales caractéristiques des huiles d'olive de Saurani étaient les suivantes : une teneur moyenne en acide oléique $(69,3 \%)$, une faible teneur en acide linoléique $(7,7 \%)$ et une teneur élevée en acide linolénique $(0,85 \%)$ avec une forte teneur totale en phénols $(522,34 \mathrm{ppm}$ sous forme d'acide gallique). Le contrôle des échantillons stockés pendant 24 mois a révélé des différences significatives entre les huiles d'olive $\mathrm{F}$ et UF en termes d'acidité libre et de peroxyde, et les huiles filtrées semblent mieux protégées contre l'hydrolyse et la détérioration oxydative. Les teneurs en acides gras libres des échantillons d'huile d'olive F et UF qui était initialement de $0,4 \%$ et a atteint $0,9 \%$ après 23 et 11 mois de stockage respectivement. Les valeurs de peroxyde des échantillons d'huile d'olive F et UF ont dépassé la limite de la norme COI ( $20 \mathrm{mEq}$ d'oxygène/ $\mathrm{kg}$ d'huile) après respectivement dix et trois mois. Les teneurs totales en phénols étaient plus élevées dans les échantillons d'UF et leur teneur diminuait avec le stockage. La lutéoline était le composé phénolique le plus abondant et les teneurs en tyrosol des échantillons de $\mathrm{F}$ et d'UF ont atteint des valeurs maximales au neuvième mois de stockage. Il semble que la filtration n'ait eu aucun effet détectable sur les teneurs en tocophérols et qu'environ $50 \%$ du $\alpha$-tocophérol ait été détruit après 24 mois de stockage.

Mots clés : Huile d'olive / saurani / composés phénoliques / tocophérol / stockage

*Correspondence: esi.1361@gmail.com 


\section{Introduction}

According to the International Olive Council, virgin olive oil (VOO) is defined that it is the oil obtained from fruits of the olive tree solely by mechanical or other physical means under conditions which do not alter the oil in any way. It means virgin olive oils are produced by the exclusion of extraction with solvents or re-esterification processes and of any mixture with other cheap oils. Therefore, virgin olive oil is the juice of the olive fruit and it is ready to be consumed almost entirely in its natural state. Indeed, olive oil extraction is a process of separating the oil from the other fruit contents (vegetation tissue, water, and solid material) with the following steps: washing, crushing, malaxation (mixing) and separation of the oil. The purpose of washing is to remove any foreign material that could damage machinery or contaminate the oil. Crushing the olives is to produce a paste with easily extracted oil droplets. Malaxation prepares the paste for separation of the oil from the pomace and optimizes oil yield through the formation of larger oil droplets and a reduction of the oil-water emulsion. The next step is extracting the oil from the paste and fruit water (water of vegetation). The oil can be extracted by pressing, centrifugation, percolation, or through combinations of different methods. After the extraction, olive oil generally needs cleaning operations using a vertical disc stack centrifuge separator and/or a filter for removing suspended solids, removing humidity and making the oil transparent and clear appearance. Indeed filtration is one of the important steps that causes qualitative and quantitative changes, especially on minor components affecting of VOO quality in terms of health benefits, shelf life, and sensory properties.

Some studies showed that filtration has positive effects such as increasing oil stability by reducing moisture and free fatty acidity, decreasing the rate of secoiridoid hydrolysis that can affect shelf life over time, eliminating undesired volatile compounds that affect the aroma of the oil, reducing rancidity of the oil, removing muddy sediment defect, contributing to clear appearance, lowering the amount of pigments thus reducing to susceptibility to photooxidation (Ngai and Wang, 2015). On the other hand, filtration has some negative effects such as decreasing oil stability due to removal of suspended solids and exposure to oxygen during filtration, decreasing water-soluble phenolic content and antioxidants that help prevent oxidation, eliminating desired volatile compounds that affect the aroma of the oil, decreasing positive attributes (fruitiness, bitterness, pungency), contributing to lighter appearance and lower intensity of the green color, decreasing pigment concentrations and limiting the ability to capture free radicals in dark, reducing shelf life due to decrease in phenolic content (Ngai and Wang, 2015). In contrast, some studies showed increases in the contents of some phenolics (oleuropein and ligstroside derivatives) in the filtered oils after vertical centrifuge treatment (Bakhouche et al., 2014). These contradictory results have attributed the reduction of the oil moisture content during the filtration and extraction method used to assess the VOO secoiridoids. These results showed that the literature lacks consensus regarding the effects of filtration on the oxidative stability, chemical and sensory properties of VOO during storing.
Recently, there is an increasing trend in natural and less processed foods due to high awareness of consumer's perception of the quality in terms of potential health properties and superior sensory characteristics. Therefore it would be expected that the demand for unfiltered VOO (veiled) will increase gradually (Tsimidou et al., 2005). Thus, it is necessary to examine the effect of filtration on the properties of VOO during storage in detail.

The aim of this study was to monitor the effects of storing on the chemical (free fatty acidity, UV absorption, peroxides and color values, total phenols, fatty acid, phenolic and tocopherol compositions) properties and sensory characteristics of VOOs after filtration performed by a filter press equipped with cellulose filters. A local Turkish olive cultivar locally grown in Hatay province was chosen for this study and processed by a boutique continues system mobile olive mill (MOM) which was designed for the national project in order to protect local olive germplasm in their nature and cultivars by creating awareness of their health benefits and quality potential. Therefore, premium quality Saurani VOO was produced with on-site milling due to virtually immediate processing. After production Saurani VOO was stored before and after filtration for 24 months.

\section{Methods and materials}

\subsection{Production of Virgin Olive Oil (VOO)}

The mobile olive mill (MOM) with a state-of-the-art Oliomio equipment was designed in order to process the olives in place immediately after harvest (Fig. 1). A special container was constructed and equipped with an olive washing machine, a knife crusher, two horizontal malaxers and a two-phase horizontal decanter (Oliomio D500, Italy) with a capacity of $500 \mathrm{~kg} / \mathrm{h}$. The MOM is an articulated lorry with a special semitrailer measuring $2438 \times 12192 \times 2896 \mathrm{~mm}$ which is divided into three separate sections. The first section is olive accepting unit including; bunker, leaf removers, washer and crusher units of the system. The second section is a processing unit including malaxer, decanter, filter, and bag-in-box filling machine. The third section is support unit placed a power plant and a water supply tank. Processing unit is a hygienic area so protected for temperature changes, dust, and odor. This hygienic area was equipped with an air conditioner, isolation, and filter ventilation systems. MOM carried by a trailer truck to orchards in the 2014-2015 season. Olive fruits were harvested by hand picking in the early harvest period and processed to cold press VOO in the MOM in a couple of hours. Olive paste was prepared after crushing by a hammer mill and the paste was mixed in the malaxer at $27^{\circ} \mathrm{C}$ for $15 \mathrm{~min}$. After decantation VOO was packaged before (Unfiltered) and after filtration (Filtered). A filter press (Oliomio Jolly 40, Italy) with the paper (Gruppo Cardenons E2, paper weight: $350 \mathrm{~g} / \mathrm{m}^{2}$, thickness: $0.81 \mathrm{~mm}$, apparent density: $0.43 \mathrm{~g} / \mathrm{cm}^{3}$, water absorption: $8 \mathrm{~g} / \mathrm{dm}^{2}$ ) was used for clarifying. Olive oil samples were filled in $250 \mathrm{ml}$ amber glass bottles (headspace: $4 \mathrm{~cm}$ ) and sparged with nitrogen to remove the influence of oxygen. The bottles were stored at room temperature $\left(18-24^{\circ} \mathrm{C}\right)$ up to 24 months. At each analysis, four bottles were removed from storage for analysis. Therefore, at each stage of analysis, a fresh bottle of olive oil was used. 

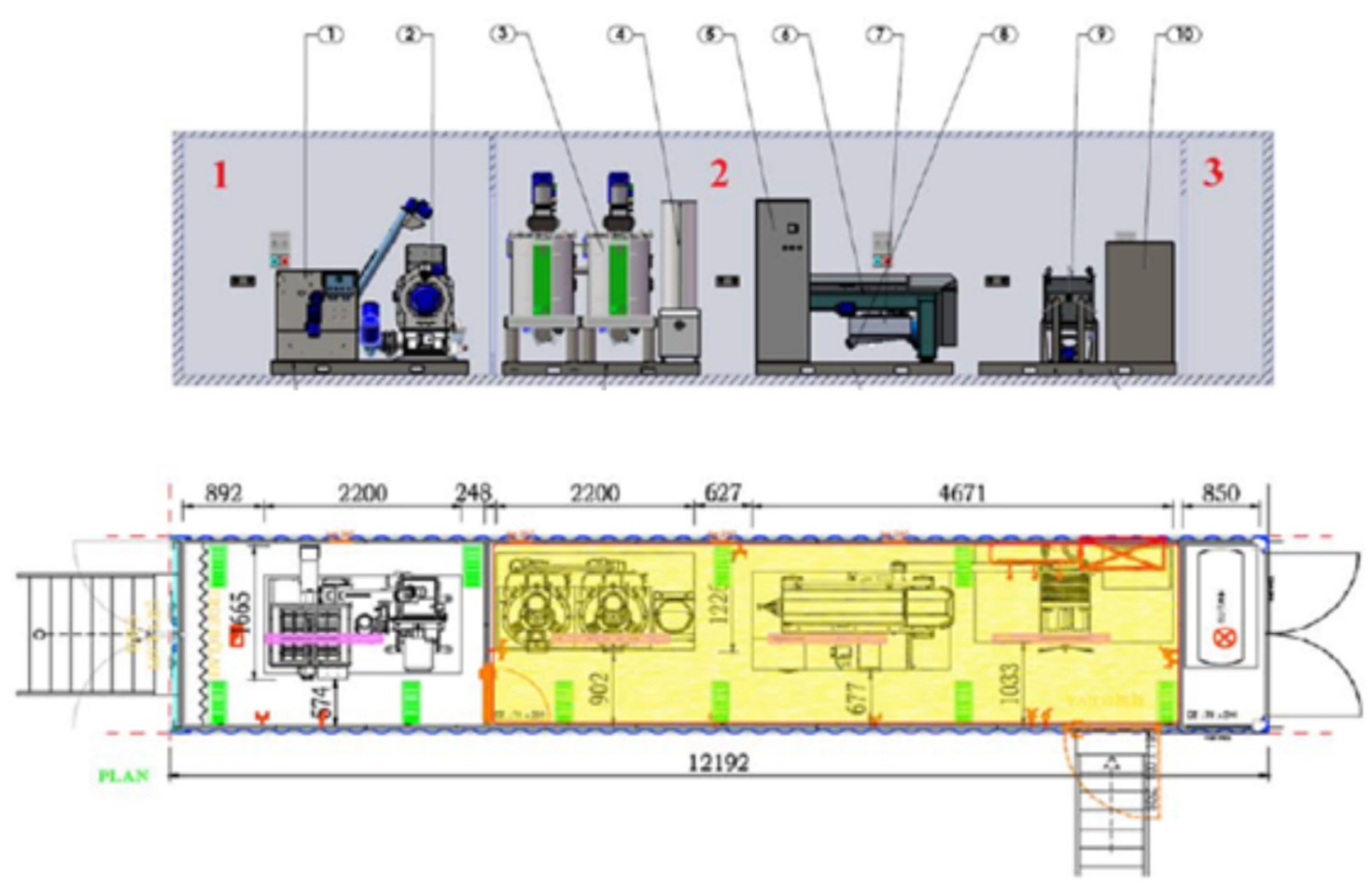

Fig. 1. Mobile Olive Oil Processing Unit (Mill on wheel). Section 1: Olive accepting unit including; bunker, leaf removers, washer (1) and crusher (2); Section 2: Processing unit including malaxer (3), decanter (6), filter (9) and filling machine (10); Section 3: Support unit placed a power plant and a water supply tank.

\subsection{Chemical analysis}

Chemical analysis including, free fatty acid content, peroxide value, moisture was performed according to the EEC 2568/91, AOCS Cd 8-53 methods, IOS 662 respectively. Color values ( $L, a, b$ values) were measured by spectrophotometer (Minolta, CM-3600d, Japan). L (lightness), $b$ (yellowness), and $a$ (redness) values were determined. UV absorbance was performed according to the IOC method COI/T.20/Doc. No. 19/Rev. 3. UV absorbance was collected in 232, 266, 270 and $274 \mathrm{~nm}$ by using UV Spectrophotometer (Agilent 8453 , USA). $\Delta K$ values were calculated with the following formula:

$$
\Delta K=\mathrm{K}_{270}-\left[\left(\mathrm{K}_{266}+\mathrm{K}_{274}\right) / 2\right] .
$$

\subsection{Total phenolic content}

The polar fraction was extracted and used for total phenolic and phenolic composition analyses. Olive oil sample $(2.5 \mathrm{~g})$ was weighed into a falcon tube. Hexane $(6 \mathrm{~mL})$ was added and shaken for $1 \mathrm{~min}$. This solution was filtered through solid phase extraction (SPE) cartridge (Superclean LC-Diol, USA) and collected in a glass tube. Then hexane $(6 \mathrm{~mL})$ and $4 \mathrm{~mL}$ hexane: ethyl acetate $(85: 15, \mathrm{v} / \mathrm{v})$ were passed through the SPE cartridge, respectively. The cartridge was washed with methanol: deionized water solution $(1: 1 \mathrm{v} / \mathrm{v})$ and the phenolic extract was evaporated (UniEquip Univapo $100 \mathrm{ECH}$, Canada). After addition of $2 \mathrm{ml}$ methanol:deionized water solution $(1: 1 \mathrm{v} / \mathrm{v})$ the tubes vortexed for $30 \mathrm{~s}$. For determination of total phenols, Folin \& Ciocalteu method was used and the results were expressed in terms of gallic acid equivalent (mg gallic acid/kg oil) (Romani et al., 2007; Inarejos-Garcia et al., 2009). Ultra high-performance liquid chromatography (Thermo Scientific Dionex Ultimate 3000, USA) and C18 column $(4.6 \mathrm{~mm}$ inner diameter $\times 250 \mathrm{~mm}$ length and $5 \mathrm{~mm}$ particle diameter; Thermo scientific acclaim 120) was used for determination of phenolic profile. Prepared phenolic extract $(1 \mathrm{~mL})$ was passed through $0.45 \mu \mathrm{m}$ microfilter (Merck, PVDF, Millipore Millex-HV, Germany) and poured into an amber vial. Column temperature was fixed at $30^{\circ} \mathrm{C}$ and acetic acid: deionized water (1:1) (A), methanol (B), acetonitril (C) were used in a gradient flow program as mobile phase. In the gradient program eluents were $2.5 \% \mathrm{~B}, 2.5 \% \mathrm{C}$, and $95 \% \mathrm{~A}$ solution up to $60 \mathrm{~min}$. Flow rate was $1 \mathrm{~mL} / \mathrm{min}$ and diode array detector (DAD) detector was set in $280 \mathrm{~nm}, 320 \mathrm{~nm}$ and $335 \mathrm{~nm}$. Apigenin, cafeic acid, gallic acid, luteolin, m-cumaric acid, p-coumaric acid, oleuropein, syringic acid, trans-ferulic acid, vanilic acid, vanillin, tyrosol, 3-hydroxy tyrosol, 3.4dihydroxy benzoic acid, 4-hydroxy benzoic acid, 4-hydroxy phenyl acetic acid were used as standards.

\subsection{Tocopherol composition}

Tocopherol composition was determined according to the AOCS Official Method Ce 8-89 (1997) by Ultra High Performance Liquid Chromatography (Thermo Scientific, Dionex Ultimate 3000, USA). LiChrosorb SI 60-5 column ( $4.6 \mathrm{~mm}$ I.D $\times 250 \mathrm{~mm}$ length and $5 \mu \mathrm{m}$ particle size) was used for analysis. Column temperature was fixed at $30^{\circ} \mathrm{C}$ during the process. Flow rate of analysis was $1 \mathrm{~mL} / \mathrm{min}$. Isopropanol: hexane $(0.5: 99.5, \mathrm{v} / \mathrm{v})$ isocratic mix was used for the mobile phase, and chromatograms were obtained at $292 \mathrm{~nm}$ 
E. Ghanbari Shendi et al.: OCL 2020, 27, 37

Table 1. Oxidative stability parameters of virgin olive oils extacted from Saurani variety during 24 months storage.

\begin{tabular}{|c|c|c|c|c|c|c|c|c|}
\hline Storage period (Month) & \multicolumn{2}{|c|}{ Free Fatty Acid Content } & \multicolumn{2}{|c|}{ Peroxide Value } & \multicolumn{2}{|c|}{$\mathrm{K}_{232}$} & \multicolumn{2}{|c|}{$\mathrm{K}_{270}$} \\
\hline 0 & $0.4 \pm 0.00^{\mathrm{f}}$ & $0.4 \pm 0.00^{\mathrm{f}}$ & $8.99 \pm 0.003^{q}$ & $11.97 \pm 0.003^{\mathrm{n}}$ & $2.0 \pm 0.00^{\mathrm{b}}$ & $2.0 \pm 0.00^{\mathrm{d}}$ & $0.19 \pm 0.00^{\mathrm{e}}$ & $0.18 \pm 0.00^{\mathrm{e}}$ \\
\hline 1 & $0.6 \pm 0.00^{\mathrm{e}}$ & $0.7 \pm 0.00^{\mathrm{e}}$ & $8.99 \pm 0.000^{q}$ & $12.02 \pm 0.038^{\mathrm{n}}$ & $2.2 \pm 0.00^{\mathrm{a}}$ & $2.3 \pm 0.00^{\mathrm{b}}$ & $0.21 \pm 0.00^{\mathrm{d}}$ & $0.21 \pm 0.00^{\mathrm{b}}$ \\
\hline 2 & $0.7 \pm 0.00^{\mathrm{d}}$ & $0.7 \pm 0.00^{\mathrm{e}}$ & $11.93 \pm 0.027^{0}$ & $14.88 \pm 0.015^{\mathrm{m}}$ & $2.2 \pm 0.00^{\mathrm{a}}$ & $2.5 \pm 0.00^{\mathrm{a}}$ & $0.21 \pm 0.00^{\mathrm{d}}$ & $0.20 \pm 0.00^{\mathrm{c}}$ \\
\hline 3 & $0.7 \pm 0.00^{\mathrm{d}}$ & $0.8 \pm 0.00^{\mathrm{d}}$ & $14.89 \pm 0.025^{\mathrm{i}}$ & $24.00 \pm 0.003^{\mathrm{a}}$ & $2.2 \pm 0.00^{\mathrm{a}}$ & $2.0 \pm 0.00^{\mathrm{d}}$ & $0.21 \pm 0.00^{\mathrm{d}}$ & $0.19 \pm 0.00^{\mathrm{d}}$ \\
\hline 6 & $0.7 \pm 0.00^{\mathrm{d}}$ & $0.8 \pm 0.00^{\mathrm{d}}$ & $17.94 \pm 0.017^{\mathrm{g}}$ & $21.01 \pm 0.019^{c}$ & $1.8 \pm 0.00^{\mathrm{d}}$ & $1.7 \pm 0.00^{\mathrm{g}}$ & $0.24 \pm 0.00^{\mathrm{b}}$ & $0.21 \pm 0.00^{\mathrm{b}}$ \\
\hline 7 & $0.7 \pm 0.00^{\mathrm{d}}$ & $0.8 \pm 0.00^{\mathrm{d}}$ & $17.97 \pm 0.001^{\mathrm{g}}$ & $20.88 \pm 0.007^{\mathrm{cd}}$ & $2.2 \pm 0.00^{\mathrm{a}}$ & $2.2 \pm 0.00^{\mathrm{c}}$ & $0.21 \pm 0.00^{\mathrm{d}}$ & $0.21 \pm 0.00^{\mathrm{b}}$ \\
\hline 8 & $0.7 \pm 0.00^{\mathrm{d}}$ & $0.8 \pm 0.00^{\mathrm{d}}$ & $17.98 \pm 0.013^{g}$ & $20.85 \pm 0.007^{\mathrm{d}}$ & $1.8 \pm 0.00^{\mathrm{d}}$ & $1.7 \pm 0.00^{\mathrm{g}}$ & $0.24 \pm 0.00^{\mathrm{b}}$ & $0.21 \pm 0.00^{\mathrm{b}}$ \\
\hline 9 & $0.7 \pm 0.00^{\mathrm{d}}$ & $0.8 \pm 0.00^{\mathrm{d}}$ & $17.99 \pm 0.005^{\mathrm{g}}$ & $20.62 \pm 0.031^{\mathrm{e}}$ & $1.3 \pm 0.00^{\mathrm{g}}$ & $1.4 \pm 0.00^{\mathrm{j}}$ & $0.10 \pm 0.00^{\mathrm{m}}$ & $0.17 \pm 0.00^{\mathrm{f}}$ \\
\hline 10 & $0.7 \pm 0.00^{\mathrm{d}}$ & $0.8 \pm 0.00^{\mathrm{d}}$ & $20.97 \pm 0.002^{\mathrm{a}}$ & $17.80 \pm 0.060^{\mathrm{f}}$ & $1.6 \pm 0.00^{\mathrm{f}}$ & $1.7 \pm 0.00^{\mathrm{g}}$ & $0.13 \pm 0.00^{\mathrm{j}}$ & $0.15 \pm 0.00^{\mathrm{h}}$ \\
\hline 14 & $0.8 \pm 0.00^{\mathrm{c}}$ & $1.0 \pm 0.01^{\mathrm{b}}$ & $20.12 \pm 0.013^{c}$ & $17.15 \pm 0.042^{\mathrm{h}}$ & $0.4 \pm 0.00^{\mathrm{k}}$ & $0.3 \pm 0.00^{0}$ & $0.14 \pm 0.00^{\mathrm{i}}$ & $0.17 \pm 0.00^{1}$ \\
\hline 15 & $0.8 \pm 0.00^{\mathrm{c}}$ & $1.0 \pm 0.01^{\mathrm{b}}$ & $19.84 \pm 0.007^{\mathrm{d}}$ & $17.02 \pm 0.021^{\mathrm{h}}$ & $0.5 \pm 0.00^{\mathrm{j}}$ & $0.4 \pm 0.00^{\mathrm{n}}$ & $0.22 \pm 0.00^{\mathrm{c}}$ & $0.21 \pm 0.00^{\mathrm{b}}$ \\
\hline 16 & $0.8 \pm 0.00^{\mathrm{c}}$ & $1.0 \pm 0.00^{\mathrm{b}}$ & $19.56 \pm 0.021^{\mathrm{e}}$ & $16.35 \pm 0.011^{\mathrm{i}}$ & $1.1 \pm 0.00^{\mathrm{h}}$ & $0.9 \pm 0.00^{\mathrm{m}}$ & $0.21 \pm 0.00^{\mathrm{d}}$ & $0.13 \pm 0.00^{\mathrm{i}}$ \\
\hline 17 & $0.8 \pm 0.00^{\mathrm{c}}$ & $1.0 \pm 0.01^{\mathrm{b}}$ & $18.48 \pm 0.031^{\mathrm{f}}$ & $16.31 \pm 0.001^{\mathrm{i}}$ & $2.0 \pm 0.00^{\mathrm{b}}$ & $1.6 \pm 0.00^{\mathrm{h}}$ & $0.17 \pm 0.00^{\mathrm{g}}$ & $0.13 \pm 0.00^{\mathrm{i}}$ \\
\hline 18 & $0.8 \pm 0.00^{\mathrm{c}}$ & $1.0 \pm 0.00^{\mathrm{b}}$ & $17.95 \pm 0.024^{\mathrm{g}}$ & $16.12 \pm 0.041^{\mathrm{j}}$ & $1.0 \pm 0.00^{\mathrm{i}}$ & $1.2 \pm 0.00^{\mathrm{k}}$ & $0.19 \pm 0.00^{\mathrm{e}}$ & $0.21 \pm 0.00^{\mathrm{b}}$ \\
\hline 19 & $0.8 \pm 0.00^{\mathrm{c}}$ & $1.0 \pm 0.00^{\mathrm{b}}$ & $17.62 \pm 0.016^{\mathrm{h}}$ & $16.12 \pm 0.011^{\mathrm{j}}$ & $1.8 \pm 0.00^{\mathrm{d}}$ & $1.7 \pm 0.00^{\mathrm{g}}$ & $0.18 \pm 0.00^{\mathrm{f}}$ & $0.15 \pm 0.00^{\mathrm{h}}$ \\
\hline 20 & $0.8 \pm 0.00^{\mathrm{c}}$ & $1.0 \pm 0.01^{\mathrm{b}}$ & $16.33 \pm 0.011^{\mathrm{i}}$ & $15.85 \pm 0.066^{\mathrm{k}}$ & $1.8 \pm 0.00^{\mathrm{d}}$ & $1.9 \pm 0.00^{\mathrm{e}}$ & $0.15 \pm 0.00^{\mathrm{h}}$ & $0.13 \pm 0.00^{\mathrm{i}}$ \\
\hline 21 & $0.8 \pm 0.00^{\mathrm{c}}$ & $1.0 \pm 0.00^{\mathrm{b}}$ & $15.49 \pm 0.034^{\mathrm{j}}$ & $15.46 \pm 0.123^{1}$ & $2.0 \pm 0.00^{\mathrm{b}}$ & $1.9 \pm 0.00^{\mathrm{e}}$ & $0.17 \pm 0.00^{\mathrm{g}}$ & $0.16 \pm 0.00^{\mathrm{g}}$ \\
\hline 22 & $0.8 \pm 0.00^{\mathrm{c}}$ & $1.0 \pm 0.01^{\mathrm{b}}$ & $14.67 \pm 0.022^{\mathrm{m}}$ & $14.95 \pm 0.012^{\mathrm{m}}$ & $1.6 \pm 0.00^{\mathrm{f}}$ & $1.8 \pm 0.00^{\mathrm{f}}$ & $0.12 \pm 0.00^{\mathrm{k}}$ & $0.22 \pm 0.00^{\mathrm{a}}$ \\
\hline 23 & $0.9 \pm 0.00^{\mathrm{b}}$ & $1.1 \pm 0.00^{\mathrm{a}}$ & $13.98 \pm 0.008^{\mathrm{n}}$ & $14.93 \pm 0.125^{\mathrm{m}}$ & $1.7 \pm 0.00^{\mathrm{e}}$ & $1.7 \pm 0.00^{\mathrm{g}}$ & $0.12 \pm 0.00^{\mathrm{k}}$ & $0.13 \pm 0.00^{\mathrm{i}}$ \\
\hline 24 & $1.0 \pm 0.00^{\mathrm{a}}$ & $1.1 \pm 0.00^{\mathrm{a}}$ & $11.56 \pm 0.025^{\mathrm{p}}$ & $11.73 \pm 0.025^{0}$ & $1.8 \pm 0.00^{\mathrm{d}}$ & $1.8 \pm 0.00^{\mathrm{f}}$ & $0.14 \pm 0.00^{\mathrm{i}}$ & $0.17 \pm 0.00^{\mathrm{f}}$ \\
\hline
\end{tabular}

Note: Different superscript letters in the same column indicate significant difference between mean values $(P<0.01), \mathrm{N}=28$.

wavelength. Analysis time and injection volume were $30 \mathrm{~min}$ and $100 \mu \mathrm{L}$, respectively. Tocopherol standards used for determination of $\alpha, \beta, \gamma$, and $\Delta$ tocopherols.

\subsection{Sensory analysis}

During storage, samples were evaluated by the panelists of the Ayvalik Olive Oil Tasting Laboratory accredited by the International Olive Council and TURKAK (Turkish Accreditation Agency) according to the method for the organoleptic assessment of VOO (COI/T.20/Doc. No. 15/Rev. 8, November 2015) monthly. Eight trained tasting panels were able to assess the oils to determine the levels of positive attributes, such as fruitiness, bitterness and pungency. Negative attributes arising due to poor quality fruit, incorrect processing or storing, such as rancidity, musty and fusty, were determined by sensory panels. Descriptors were evaluated on a $0-10$ intensity scale (a number between 0 and 10).

\subsection{Statistical analysis}

Statistical analysis was performed by SPSS 17 (SPSS Inc.Chicago, IL) statistical software and using One-way ANOVA method. All analyses were performed at least duplicate. and differences among all groups were determined by Duncan test.

\section{Results}

\subsection{Chemical analyses}

Free acidity, peroxide, and UV absorbance values of the olive oils produced in the MOM were shown in Table 1. Both filtered and unfiltered Saurani VOOs were classified as virgin olive oil in first year of storing according to the results of moisture and free acid content, peroxide and UV absorption values (International Olive Oil Council standards). Moisture contents $(\%)$ were $0.06 \pm 0.01$ and $0.08 \pm 0.00$ for filtered $(F)$ and unfiltered (UF) samples, respectively. Although the paper filter caused to a slight decrease on moisture, but its effects were not statistically significant $(p>0.05)$. It is well-known that water accelerates the chemical hydrolysis of VOO samples resulting in increasing free fatty acidity and deterioration of sensory properties.

Free fatty acid content of filtered and unfiltered VOO samples of Saurani (Hatay) showed the same trend during the first year (Tab. 1), but UF sample downgraded and it was classified as virgin olive oil after the eleventh month. Free acidity of filtered sample was lower than 0.8 until twenty-third 
month. This indicated that free acidity value increased more rapidly in the unfiltered ones due to higher moisture content. This result is agreement with the earlier studies indicating that free acidity increases depending on cultivar, the packaging material, storage conditions and time (Lavelli et al., 2006; Méndez and Falqué, 2007; Clodoveo et al., 2007; Baiano et al., 2014). Peroxide values (PV) changed significantly both $F$ and UF samples during two years $(p<0.01)$ and reached higher values in the UF samples at early months of storage, after a year PV of F and UF samples showed a declining trend up to end of storage (Tab. 1). The PV reached to maximum values in third and tenth months for $\mathrm{F}$ and UF olive oils respectively. Significant increases were reported on the PV of olive oil samples during short-term (30 days) and long-term (six years) storage in different packaging materials at different conditions (Okogeri and Tasioula-Margari, 2002; Lavelli et al., 2006; Clodoveo et al., 2007; Baiano et al., 2014).

UV absorbance values $\left(\mathrm{K}_{232}\right.$ and $\left.\mathrm{K}_{270}\right)$ which are an indicator of secondary products of oxidation (conjugated dienes and trienes) changed during storage significantly $(p<0.01)$, During the storage, $\mathrm{K}_{232}$ and $\mathrm{K}_{270}$ values were below the limits 0.22 and 0.25 for all samples, respectively. $\mathrm{K}_{232}$ values of UF oils were higher during the early months and a decreasing trend was seen both $F$ and UF samples up to fifteenth month (Tab. 1). After a sharp increase in sixteenth months, $\mathrm{K}_{232}$ values were decreased near to end of the storage. Significant changes were seen $\mathrm{K}_{270}$ values, but the results were comparable for both $\mathrm{F}$ and UF oils during the early months. $\Delta K$ values of all samples were zero or below zero (results are not shown). Oxidative deterioration of olive oils ( $\mathrm{PV}, \mathrm{K}_{232}$, and $\mathrm{K}_{270}$ ) during filtration with cotton layer and filter paper or cross-flow filtration through inorganic membranes seemed to be negligible or moderate (Brenes et al., 2001; Tsimidou et al., 2005; Fregapane et al., 2006; Brkić Bubola et al., 2017). Tsimidou et al. (2005) suggested unfiltered oils were better against to oxidative stability. Fregapane et al. (2006) affirmed that filtration caused an increase in the rate of peroxide formation. Decreasing oxidative stability with filtration sometimes resulted in downgraded olive oils which were no longer extra virgin olive oils during storage.

Olive fruit fly (Bactrocera oleae) is the most serious insect pest of the cultivated olive fruits in the world. This insect pest affects the olive tree cultivation, and led to serious qualitative and quantitative consequences with economic impacts and losses. Their larvae are oligophagous and feed inside the fruit, destroying the pulp and allowing the entry of secondary bacteria and fungi that contribute to rot the fruit and to degrade the oil. Free fatty acid content, peroxide value, and UV absorbance increased with the degree of olive fly attack (Mraicha et al., 2010; Medjkouh et al., 2016).

\subsection{Color analysis}

In spite of the fact that color is not regarded as an important quality characteristic for VOO, it has a great effect on consumer acceptance. Color of virgin olive oils is related to olive maturity and process conditions. Analysis of color $(L$, $a$ and $b$ values) showed that the color of olive oil samples altered significantly during storage (Tab. 2). Color of F samples changed from green to yellow with storage. It has been attributed that decomposition of color pigments such as chlorophylls, pheophytins, xanthophylls, and carotenes (Boskou, 2006). Although significant fluctuations were observed in $L$ (lightness), a (redness) and $b$ (yellowness) values of all samples during storage, generally, unfiltered samples had lower $L$ and higher $a$ values indicating they were dark green. After the highest $b$ value in eighth months, a decreasing trend in $b$ values was measured for all samples. Tsimidou et al. (2005) reported no significant changes in chlorophyll and carotenoid concentration in dark at laboratory conditions. Gómez-Caravaca et al. (2007) reported that paper filtration resulted in higher lightness and poor green color.

\subsection{Tocopherol profile}

Tocopherols $(\alpha, \beta, \gamma)$ profile of Saurani VOO were determined every two months in the first year and every three months in the second year (Tab. 3). The results showed that tocopherols contents $(\alpha, \beta, \gamma)$ decreased with increasing storage time. The lowest tocopherols contents were obtained after two years of storage. The loss was about $50 \%$ in $\alpha$-tocopherol content and; 94.8 and $87.9 \%$ of $\beta$-tocopherol and 94 and $90 \%$ of $\gamma$-tocopherol contents were decomposed in $\mathrm{F}$ and UF samples after storage. Filtration had no detectable effect on $\alpha$-tocopherol content. $\beta$-tocopherol content was higher in $\mathrm{F}$ samples. In contrast, the amount of $\mathrm{\gamma}$-tocopherol was higher in UF samples. These results were in agreement with the earlier researchers (Psomiadou et al., 2000; Okogeri and Tasioula-Margari, 2002; Rastrelli et al., 2002; Baiano et al., 2014).

\subsection{Total polyphenol}

Total polyphenols contents of the samples were presented in Figure 2. The highest total polyphenol values were determined in fresh oils and progressive decreases were observed during storage. But the decreases were not dramatic as well as tocopherols, after two years $40 \%$ and $30 \%$ of total polyphenols were decomposed in F and UF samples, respectively. Unfiltered samples had higher total polyphenol content indicating filtration had a significant effect. It is reported that the total phenolic content of Italian olive oil varied from 50 to $1000 \mathrm{ppm}$ and classified as $50-200 \mathrm{ppm}$ (low), 200-500 ppm (middle) and 500-1000 ppm (high). (Montedoro et al., 1992). The total phenol content of commercial olive oil was about $400 \mathrm{mg}$ of CA/ $\mathrm{kg}$. Lower total phenolic contents were reported for some monocultivar Turkish olive oils ranged from 64 to $321 \mathrm{mg}$ of CA/kg for Halhali, Egriburun, Hasebi, Karamani and Saurani olive oils (García et al., 2003; Arslan and Schreiner 2012). The total phenol contents of oils were affected by depending on cultivars, geographic origin, agronomic techniques, olive ripening, extraction methods, and storage conditions. After a short term or long term storage significant decreases in total polyphenols were reported for monocultivar and commercial olive oils by Morelló et al. (2004), Clodoveo et al. (2007), Abdalla et al. (2014) and Baiano et al. (2014). In a recent study, it was reported that the medium-high concentrations of total phenols in the veiled (unfiltered) Italian and Greek 
E. Ghanbari Shendi et al.: OCL 2020, 27, 37

Table 2. Color values ( $L, a, b$ values) of filtered and unfiltered Saurani during 24 months of storage period.

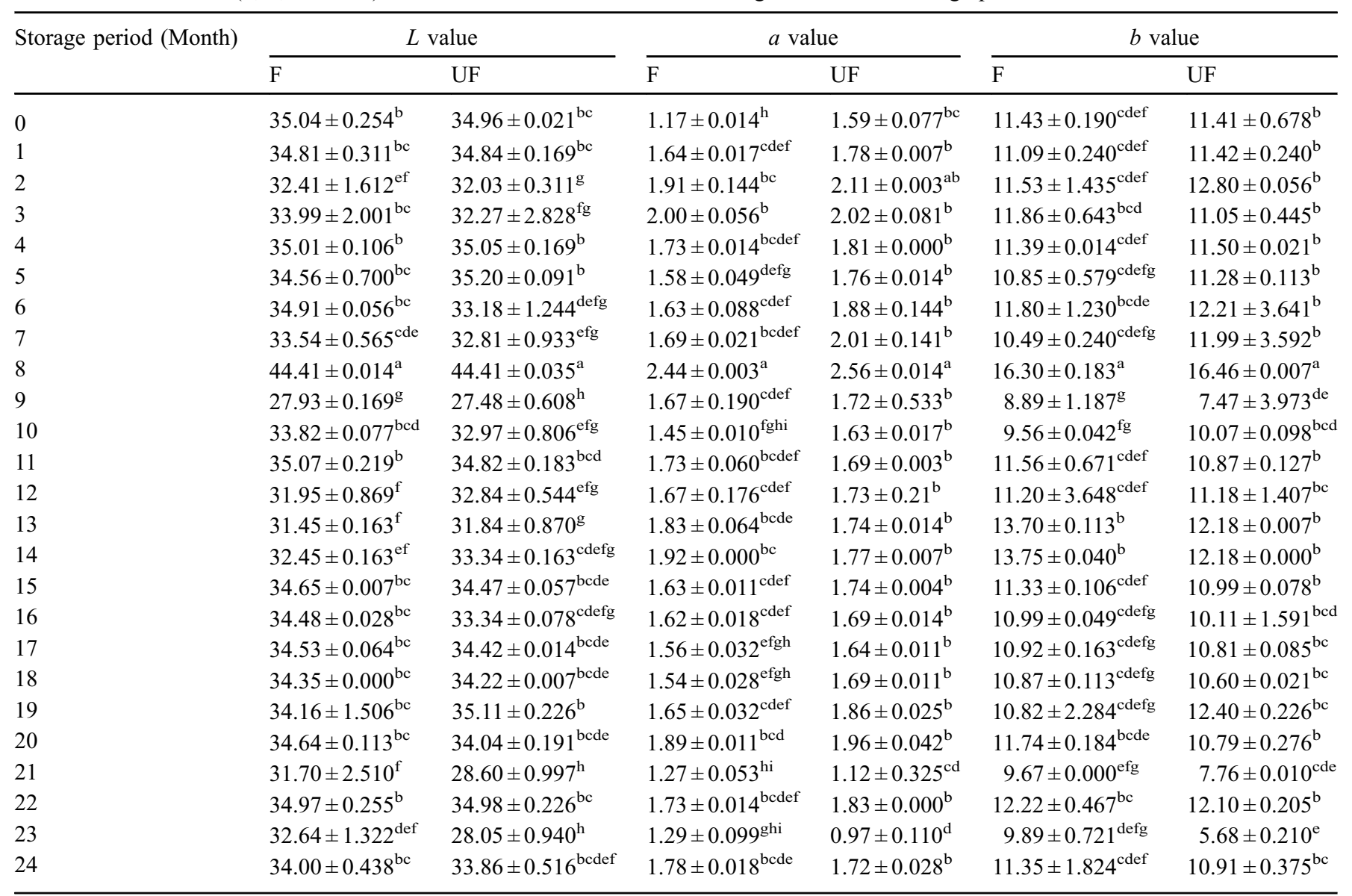

Note: Different superscript letters in the same column indicate significant difference between mean values $(P<0.01), \mathrm{N}=28$.

VOOs at the beginning of the storage period guaranteed a higher quality of the product at the end of shelf life test (Venziani et al., 2018).

\subsection{Phenolic profiles}

Phenolics have been associated with oxidation stability, sensory properties of VOO and health promoters as a natural antioxidant (Maga, 1978; Nergiz and Unal, 1991). Changes in the concentrations of phenolic compounds were monitored during storage and the results were presented in Tables 4 and 5. The phenolics present in VOO were determined as nine phenolic acids (3,4-dihydroxy benzoic acid, 4-hydroxy benzoic acid, 4-hydroxy phenyl acetic acid, syringic acid, trans-ferulic acid, o-, m- and p- coumaric acids and vanillin), two phenolic alcohols (tyrosol, 3-hydroxytyrosol), two flavonoids (luteolin and apigenin) and one secoiridoid (oleoropein). Qualitative and quantitative differences were observed in both filtered and unfiltered samples and individual phenols also varied depending on storage time suggesting that filtration and storage caused to change on the phenolic profile. As the expected amount of the phenolics in fresh VOO were higher in UF sample than F ones except trans ferulic acid and o-coumaric acid. Filtration caused to a decrease in the content of some phenolic acids such as 3,4-dihydroxy benzoic acid, syringic acid, and o-coumaric acid, they were present in very low level, in all cases $1<\mathrm{ppm}$ in both F and UF olive oils. In fresh oils, luteolin was the most abundant phenolics in the $\mathrm{F}$ (294.74 ppm) and UF (347.57 ppm) samples and apigenin was also detected at low levels. The amount of these compounds in VOO is very low and generally ranges between 0 and $10 \mathrm{mg}$ per $\mathrm{kg}$ of oil (Bendini et al., 2009). Syringic acid and vanillin were absent in fresh F sample. 4-hydroxy benzoic acid and $\mathrm{m}$ coumaric acid were found at high concentrations as compared to other phenolic acids. Oleoropein, tyrosol, and 3-hydroxytyrosol were not detected in fresh VOO before and after filtration.

Regarding to the influence of the storage time on the individual phenolics of both F and UF samples presented an increasing trend for 3,4-dihydroxy benzoic acid and 4-hydroxy benzoic acid. However, 3,4-dihydroxy benzoic acid content of F sample increased up to seventh month; then started to decrease and 4-hydroxy phenyl acetic acid content reached at maximum value at sixth month. o-coumaric and m-coumaric acids contents of $F$ samples increased up to seventh and eighth months, respectively. Although trans-ferulic acid was only detected at fifth month for UF sample, its content seemed to 
Table 3. Tocopherol Content of Saurani (Hatay) monocultivar during 24 months of storage.

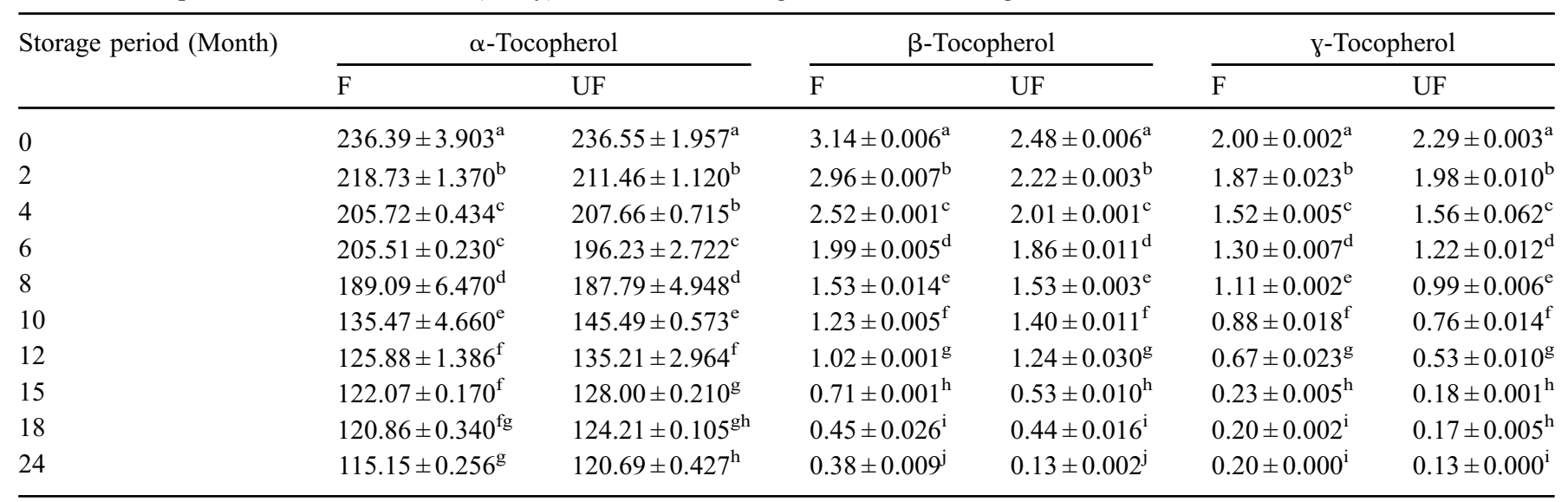

Note: Different superscript letters in the same column indicate significant difference between mean values $(P<0.01), \mathrm{N}=28$.

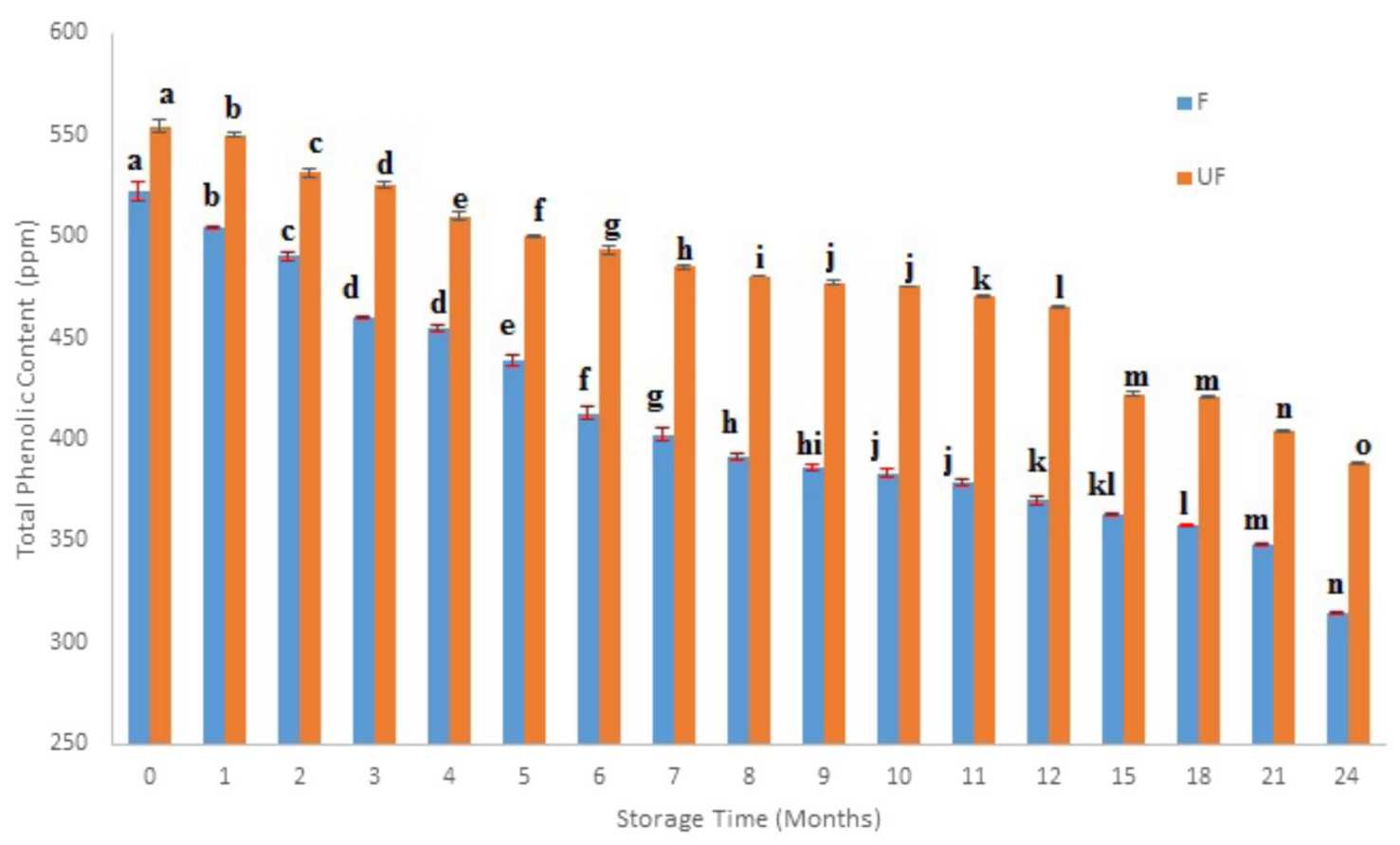

Fig. 2. Changes in total phenolic content of VOOs during 24 months of storage (ppm).

have maximum value at the end of first year for $\mathrm{F}$ sample. Similar increasing trend was seen for oleuropein and its content reached maximum at seventh and ninth months both UF and F samples, respectively. However, tyrosol contents of F and UF samples were maximum (21.37 ppm and $22.89 \mathrm{ppm})$ at 9th month. Although 3-hydroxytyrosol content of UF sample was under the detection limit up to one year (twelfth month) it reached maximum levels up to $122.22 \mathrm{ppm}$ at the end of the storage (twenty-fourth months). Tyrosol and 3-hydroxytyrosol contents were too higher than those obtained for Turkish olive oil cultivars which were ranged from 0.18 to $1.57 \mathrm{mg} / \mathrm{kg}$ (Dağdelen et al., 2013). Average secoiridoits concentration may range from a few ppm to 800-900 ppm (Servili et al., 2002). Indeed, phenolic alcohols such as hydroxytyrosol and tyrosol are present in fresh virgin olive oils at relatively low concentrations, but their amount is increased after storage, due to hydrolysis of secoiridoids such as dialdehydic form of elenolic acid linked to hydroxytyrosol (3,4-DHPEAEDA) or tyrosol ( $p$-HPEA-EDA) and an isomer of the oleuropein aglycon (3,4-DHPEA-EA) and hydroxytyrosol acetate $(3,4-$ DHPEA-AC) indicating more active participation in the oxidative processes as they were more easily oxidized (Cinquanta et al., 1997; Mulinacci et al., 2013). The formation of simple phenols due to the hydrolysis of their secoiridoid 


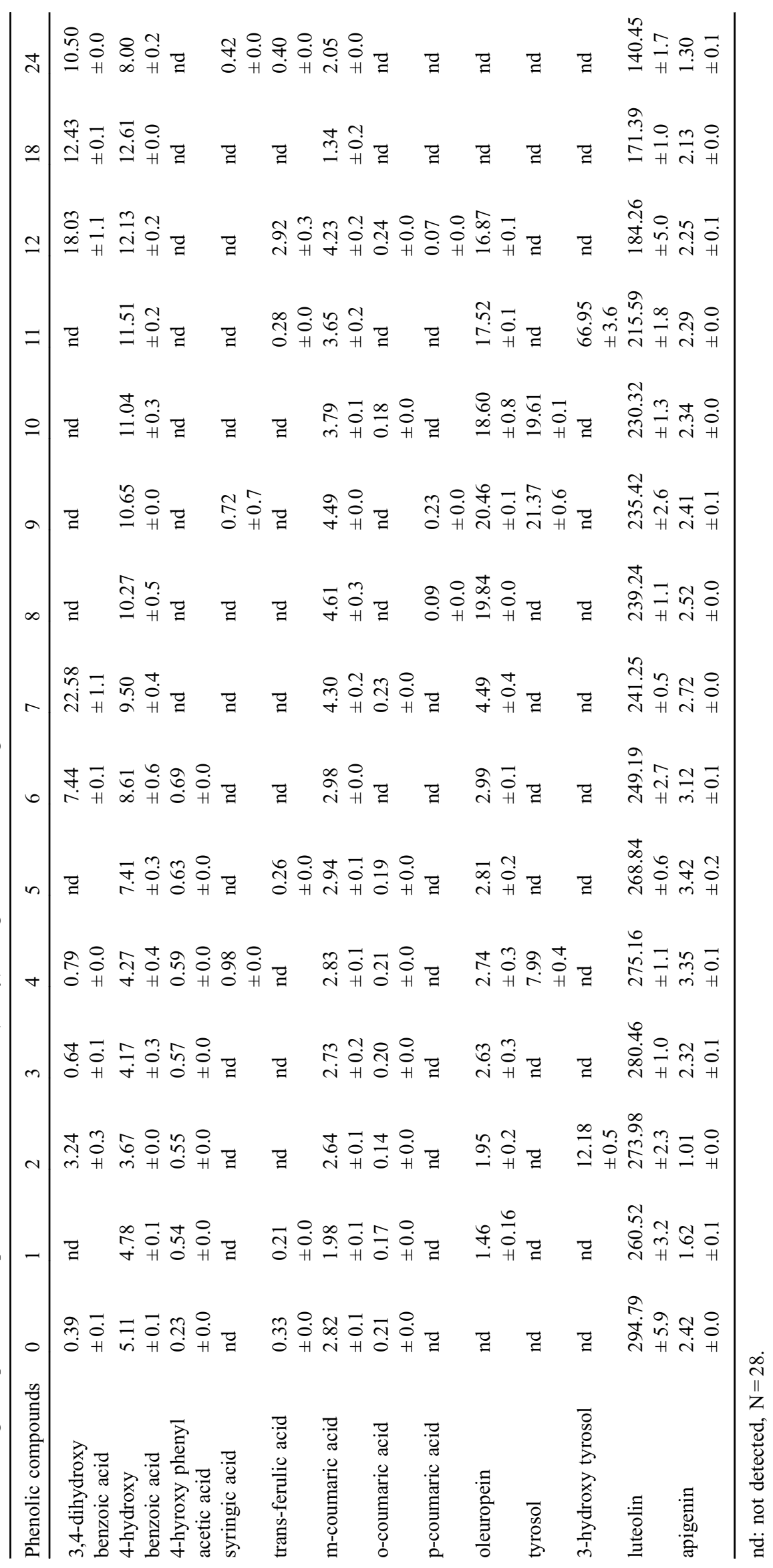




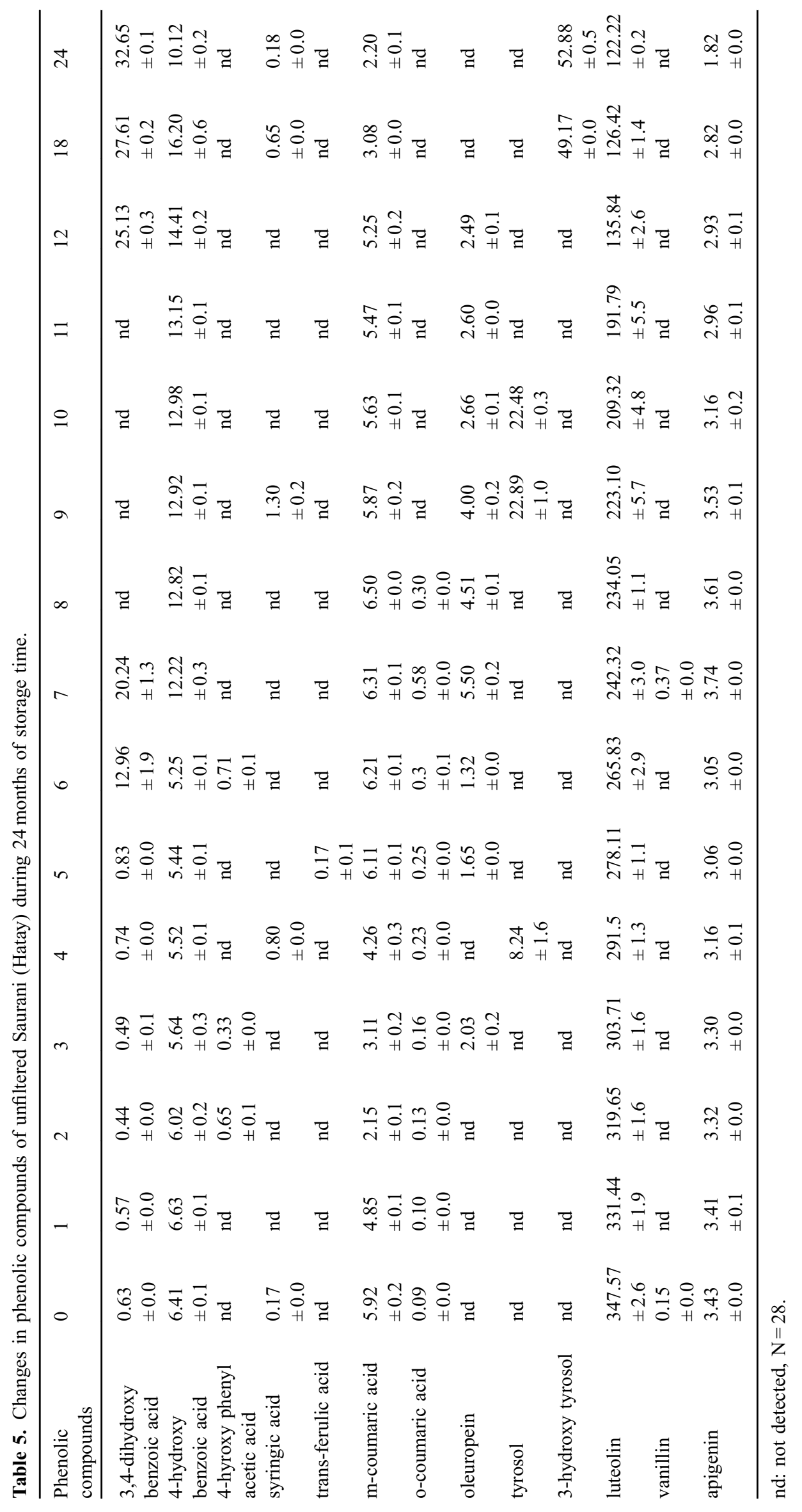




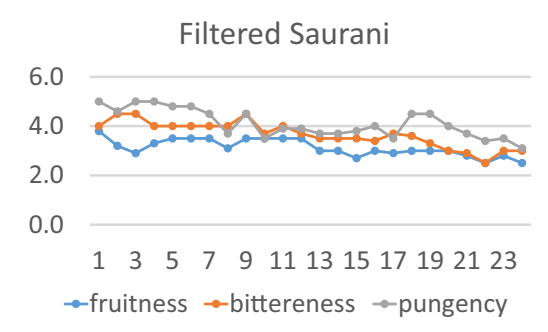

Fig. 3. Sensory values of filtered Saurani (Hatay) olive oils during 24 months of storage.

derivatives was also greater in UF sample $(22.89 \mathrm{ppm}$ and $20.46 \mathrm{ppm}$ in UF and F samples, respectively, after 9 months of storage). The main reason for this effect could attributed to the filtration process. Filtration process can decrease water-soluble phenolic content and antioxidant in VOO (Ngai and Wang, 2015).

Lower luteolin and apigenin contents were determined both $\mathrm{F}$ and UF samples at the end of storage as compared to fresh samples. The decreases of for luteolin contents were calculated as $53 \%$ and $65 \%$ for $\mathrm{F}$ and UF samples, respectively. The reduction of luteolin content of UF sample was higher than that of $\mathrm{F}$ sample. The decrease in luteolin content was more obvious as compared to apigenin.

The results obtained in this study are agreement in the report that Saurani was superior cultivar due to high total phenolics, secoiridoid aglycones, $\alpha$-tocopherol and antioxidant activity (Arslan and Schreiner, 2012).

Olive fruit fly (Bactrocera oleae) is the most serious insect pest of the cultivated olive fruits in the world. This insect pest affects the olive tree cultivation and led to serious qualitative and quantitative consequences with economic impacts and losses. Free fatty acid content, peroxide value, and UV absorbance increased with the degree of olive fly attack, while tocopherol isomers, phenolic compounds, and antioxidant activity of olive oil decreased as compared to undamaged (Mraicha et al., 2010, Medjkouh et al., 2016).

\subsection{Sensory analysis}

Positive attributes (fruitiness, bitterness, and pungency) and negative attributes (rancidity, musty and fusty, etc.) of VOO were determined by the trained tasting panel and the results were presented in Figures 3 and 4. Although F and UF VOO had comparable scores for bitterness and fruitiness, pungency was dominant before storing. This can be attributed to high total polyphenol content ( $>500 \mathrm{ppm}$ ) of Saurani VOO which are correlated with bitterness and pungency. These properties which are key sensory attributes associated with olive oil style. Olive oil classification as mild, medium or robust can be associated to the total phenol content. Robust olive oils tend to have a total phenol level above $300 \mathrm{mg} / \mathrm{kg}$, while oils perceived as mild have levels below $180 \mathrm{mg} / \mathrm{kg}$. Therefore Saurani VOO can be classified as robust olive oil in terms of sensory properties.

F sample seemed to be stable during the first year of storage in terms of fruitiness and bitterness, however, pungency score decreased from 5 to 3.9 scores. At the end of storage (24th month) bitterness and fruitiness scores altered from 4 to 2.5 and 4 to 2 , respectively. A similar trend was observed in UF

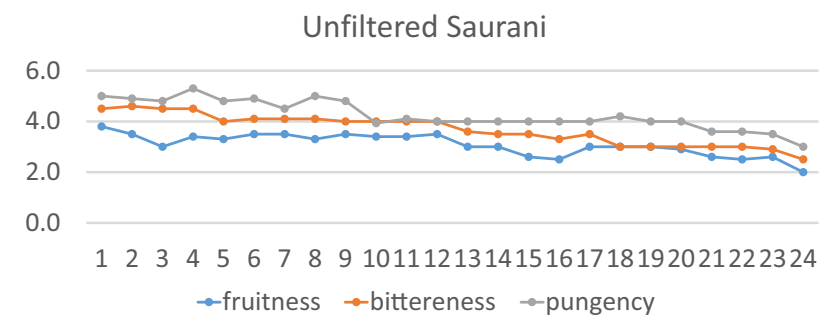

Fig. 4. Sensory values of unfiltered Saurani (Hatay) olive oils during 24 months of storage.

samples, however, the decreases in pungency, bitterness and fruitiness scores were limited as compared to F sample (from 5 to $3,4.5$ to 3 , and 3.8 to 2.5 respectively). Negative points of sensory values are attributed to olive fly damages (Mraicha et al., 2010).

\section{Conclusion}

In this project, mobile olive oil processing unit (TEM Oliomio 500-2GV, Italy) was used for extraction of VOO from Saurani olive cultivar. Therefore, Saurani which is less known cultivar in Turkey was used to produce virgin olive oil with premium quality and effects of the filtration and the storage time on its quality and sensory properties was investigated. In the mobile olive oil processing unit water was not added for oil separation, therefore, VOO with premium quality was obtained with lower environmental impact (lesser quantity of vegetation water produced) and lower investment and operating costs, the latter due to reduced consumption of water and energy.

The high total phenol contents $(>500 \mathrm{ppm})$ and sensory scores of Saurani VOO make the VOO of this cultivar superior, however, their oxidative stability decreased with storage. Peroxide values of $F$ and UF olive oils were exceeded the limits of IOC standard ( $20 \mathrm{mEq}$ oxygen $/ \mathrm{kg}$ oil) after tenth and third months, respectively. This may be related to olive fly (Bactrocera oleae) which was common disease in Hatay province in 2013-2014 harvest season.

Filtration and storage time had affected the chemical composition and sensory properties of Saurani VOO. Although filtration removes the suspended solids, this can also cause changes in the oil, especially on the minor fraction, such as reduction of tocopherols, total phenols, and phenolic compounds (Sinesio et al., 2015). Results regarding the influence of VOO filtration through the cotton layer or filter paper on phenol concentration are not consistent in the literature. In this study results of total phenolic content, phenolic profile and sensory evaluation suggested that a part of polyphenols were removed due to paper filtration. Filtration caused a decrease in moisture content and the rate of peroxide formation. Especially dehydration could help to prolong the shelf life of high-quality oils (Ngai and Wang, 2015).

\section{Abbreviation}

$\begin{array}{ll}\text { F } & \text { Filtered } \\ \text { UF } & \text { Unfiltered } \\ \text { VOO } & \text { Virgin Olive Oil }\end{array}$


Acknowledgment. The authors are also grateful for the financial supports that were provided by the Republic of Turkey, Ministry of Science, Industry, and Technology for financial supports of SANTEZ-0560-STZ-2013-2 project.

\section{References}

Abdalla IIH, Khaddor M, Boussab A, Garrouj DE, Ayadi M. 2014. The effect of storage time on the quality of olive oil produced by cooperatives for olive growers in the North of Morocco. Asian J Agric Food Sci 02: 129-138.

American Oil Chemists' Society (AOCS). 2003. Official Method for determining peroxide value Acetic Acid-Chloroform, Cd 8-53.

American Oil Chemists' Society (AOCS). 1997. Determination of tocopherols and tocotrienols in vegetable oils and fats by HPLC. AOCS Official Method Ce 8-89.

Arslan D, Schreiner M. 2012. Chemical characteristics and antioxidant activity of olive oils from Turkish varieties grown in Hatay province. Sci Horticult 144: 141-152. https://doi.org/ 10.1016/j.scienta.2012.07.006.

Baiano A, Terracone C, Viggiani I, Del Nobile MA. 2014. Changes produced in extra-virgin olive oils from cv. Coratina during a prolonged storage treatment. Czech J Food Sci 32(1): 1-9.

Bakhouche A, Lozano-Sánchez J, Ballus CA, et al. 2014. A new extraction approach to correct the effect of apparent increase in the secoiridoid content after filtration of virgin olive oil. Talanta 127: 18-25.

Bendini A, Cerretani L, Salvador MDM, Fregapane G, Lercker G. 2009. Stability of the sensory quality of virgin olive oil during storage: An overview. Ital Food Beverage Technol 21: 389-406.

Boskou D. 2006. Olive oil-Chemistry and technology. AOCS Press. https://doi.org/10.1159/000097916.

Brenes M, Garcia A, Garcia P, Garrido A. 2001. Acid hydrolysis of secoiridoid aglycons during storage of virgin olive oil. J Agric Food Chem 49(11): 5609-5614.

Brkić Bubola K, Lukić M, Mofardin I, Butumović A, Koprivnjak O. 2017. Filtered vs. naturally sedimented and decanted virgin olive oil during storage: Effect on quality and composition. $L W T-F o o d$ Sci Technol 84: 370-377. https://doi.org/10.1016/j. lwt.2017.05.069.

Cinquanta L, Esti M, Notte ELA. 1997. Evolution of phenolic compounds in virgin olive oil during storage. J Am Oil Chem Soc 74: 1259-1264. https://doi.org/10.1007/s11746-997-0054-8.

Clodoveo ML, Delcuratolo D, Gomes T, Colelli G. 2007. Effect of different temperatures and storage atmospheres on Coratina olive oil quality. Food Chem 102: 571-576. https://doi.org/10.1016/j. foodchem.2006.05.035.

Dağdelen A, Tumen G, Ozcan MM, Dundar E. 2013. Phenolics profiles of olive fruits (Olea europaea L.) and oils from Ayvalık, Domat and Gemlik varieties at different ripening stages. Food Chem 136: 41-45.

EEC Regulation No. 796 of 6 May 2002 on change. E.C. Regulation No. 2568/91. 2002. Off J Eur Commun, L 128/8 15/05/02, Brussels, Belgium.

Fregapane G, Lavelli V, León S, Kapuralin J, Desamparados Salvador M. 2006. Effect of filtration on virgin olive oil stability during storage. Eur J Lipid Sci Technol 108(2): 134-142.

García A, Brenes M, García P, Romero C, Garrido A. 2003. Phenolic content of commercial olive oils. Eur Food Res Technol 216: 520 525. https://doi.org/10.1007/s00217-003-0706-3.
Gómez-Caravaca AM, Cerratani L, Bendini A, Segura-Carretero A, Fernández-Gutiérrez A, Lercker G. 2007. Effect of filtration systems on the phenolic content in virgin olive oil by HPLCDAD-MSD. Am J Food Technol 2: 671-678.

Inarejos-Garcia AM, Androulaki A, Salvador MD, Fregapane G, Tsimidou MZ 2009. Discussion on the objective evaluation of virgin olive oil bitterness. Food Res Int 42: 279-284. https://doi. org/10.1016/j.foodres.2008.11.009.

International Olive Council (IOC) Regulation. 2015. Sensory analysis of olive oil, method for the organoleptic assessment of virgin olive oil, COI/T.20/Doc. No. 15/Rev. 8 .

International Olive Council (IOC) Regulation. 2015. "Spectrophotometric investigation in the ultraviolet". COI/T.20/Doc. No. 19/ Rev. 3.

International Organization for Standardization. 2016. "Determination of the moisture and volatile matter". No. 662.

Lavelli V, Fregapane G, Salvador MD. 2006. Effect of storage on secoiridoid and tocopherol contents and antioxidant activity of monovarietal extra virgin olive oils. J Agric Food Chem 54: 3002-3007.

Maga JA. 1978. Simple phenol and phenol compounds in food flavor. Crit Rev Food Sci Nutr 10: 323-372.

Medjkouh L, Tamendjari A, Keciri S, Santos J, Antónia Nunes M, Oliveira MBP. 2016. Effect of olive fruit fly (Bactrocera oleae) on quality parameters, antioxidant and antibacterial activities of olive oil. Food Funct 1-29.

Méndez AI, Falqué E. 2007. Effect of storage time and container type on the quality of extra-virgin olive oil. Food Control. https://doi. org/10.1016/j.foodcont.2005.12.012.

Montedoro G, Servili M, Baldioli M, Miniati E. 1992. Simple and hydrolyzable phenolic compounds in virgin olive Oil. 1. Their extraction, separation, and quantitative and semiquantitative evaluation by HPLC. J Agric Food Chem 40: 1571-1576. https:// doi.org/10.1021/jf00021a019.

Morelló JR, Motilva MJ, Tovar MJ, Romero MP. 2004. Changes in commercial virgin olive oil (cv Arbequina) during storage, with special emphasis on the phenolic fraction. Food Chem 85: $357-$ 364. https://doi.org/10.1016/j.foodchem.2003.07.012.

Mraicha F, Ksantini M, Zouch O, Ayadi M, Sayadi S, Bouaziz M. 2010. Effect of olive fruit fly infestation on the quality of olive oil from Chemlali cultivar during ripening. Food Chem Toxicol 48: 3235-3241.

Mulinacci N, Ieri F, Ignesti G, et al. 2013. The freezing process helps to preserve the quality of extra virgin olive oil over time: A case study up to 18 months. Food Res Int 54: 2008-2015. https://doi. org/10.1016/j.foodres.2013.03.052.

Ngai C, Wang S. 2015. Filter or not? A review of the influence of filtration on extra virgin olive oil. UC Davis Olive Center, Igarss 2014: 1-14.

Nergiz C, Unal K. 1991. Determination of phenol acids in virgin olive oil. Food Chem 39: 237-240.

Okogeri O, Tasioula-Margari M. 2002. Changes occurring in phenolic compounds and alpha-tocopherol of virgin olive oil during storage. J Agric Food Chem 50: 1077-1080. https://doi.org/ 10.1021/jf010895e.

Psomiadou E, Tsimidou M, Boskou D. 2000. Alpha-tocopherol content of Greek virgin olive oils. J Agric Food Chem 48: 17701775 .

Rastrelli L, Passi S, Ippolito F, Vacca G, Simone F De. 2002. Rate of degradation of r-tocopherol, squalene, phenolics, and polyunsaturated fatty acids in olive oil during different storage conditions. $J$ Agric Food Chem 5566-5570. 
Romani ANR, Apucci CHL, Antini CLC, Eri FRI, Ulinacci NAM, Isioli FRV. 2007. Evolution of minor polar compounds and antioxidant capacity during storage of bottled extra virgin olive oil. J Agric Food Chem 55: 1315-1320.

Sinesio F, Moneta E, Raffo A, et al. 2015. Effect of extraction conditions and storage time on the sensory profile of monovarietal extra virgin olive oil (cv Carboncella) and chemical drivers of sensory changes. LWT-Food Sci Technol 63: 281-288. https:// doi.org/10.1016/j.lwt.2015.03.025.

Tsimidou MZ, Georgiou A, Koidis A, Boskou D. 2005. Loss of stability of "veiled" (cloudy) virgin olive oils in storage. Food Chem 93: 377.

Venziani G, Esposto S, Minnocci A, et al. 2018. Compositional differences between veiled and filtered virgin olive oils during a simulated shelf life. LWT-Food Sci Technol 94: 87-95.

Cite this article as: Ghanbari Shendi E, Sivri Ozay D, Ozkaya MT. 2020. Effects of filtration process on the minor constituents and oxidative stability of virgin olive oil during 24 months storage time. OCL 27: 37. 